Síntese - Rev. de Filosofia

v. 31 N. 99 (2004): 27-44

\title{
DEVERES DE VIRTUDE E RAZÃO \\ PRÁTICA EM KANT
}

\author{
José N. Heck \\ UFG-CNPq/ U CG
}

Resumo: Com vistas à amplitude das objeções de H. Allison no âmbito da concepção tardia da ética kantiana, o presente trabalho propõe-se mostrar que o filósofo alemão sustenta a ordenação de fins como deveres com 0 interesse da razão no fato de ela mesma conter fins, ou seja, no intuito de mostrar que os fins propostos pela razão pura prática coincidem com a aptidão prática da razão de fornecer fins, tornando cada homem merecedor da vida que acolhe a seu bel-prazer.

Palavras-chave: Kant, deveres de virtude, razão prática, vontade, moral, ética.

Abstract: In lieu of the broadness of H. Allison's objections within the frame of Kant's late conception of Ethics, this paper tries to show that the German philosopher defends a rearrangement of ends as duties with the interest of reason upon the fact that reason itself holds ends, that is, with the intention to show that the ends proposed by the pure practical reason coincide with her practical capacity of providing ends, making each man worthy of the life that he embraces freely.

Key words: Kant, duties of virtue, practical reason, will, morals, Ethics. 
$m$ "Kant's doctrine of obligatory ends" ${ }^{1}, \mathrm{H}$. Allison entende a expressão máxima de fins, contida no princípio supremo da Doutrina da virtude, como "simply policy to make something one's end" 2 . Para Allison, o princípio, "age segundo uma máxima de fins que possa ser tida como uma lei universal para qualquer um" $^{3}$, perfaz uma petição de princípio, de acordo com a qual constitui fim obrigatório aquele fim para o qual há uma lei que exige ser aceita. 0 aludido princípio redunda para Kant em fins obrigatórios, vale dizer, o princípio supremo da Doutrina da virtude "clearly assumes that there are such ends" ${ }^{\text {. Segundo Allison, são }}$ exatamente esses os fins procurados por Kant para fundamentar o princípio assinalado.

Por mais que se concorde com a conclusão, continua fazendo diferença falar de uma lei para ter um fim e falar de uma lei que prescreve a acolhida desse fim. A diferença consiste em que uma eventual lei, ao tomar algo por fim, pode e deve ser pensada independentemente da aceitação ou rejeição de quaisquer fins possíveis. De modo semelhante pode ser aceita a afirmação do scholar americano de que Kant assegura fins que ainda procura, contanto que se considere que o fim, para cuja apropriação pode haver uma lei, é idêntico ao fim que eu devo ter. 0 texto kantiano supõe 0 conceito de fim obrigatório, mas não - como Allison admite - que tais fins existam. 0 intérprete não apenas confunde fins contidos em máximas com um ser de máximas para fins, mas também assume que Kant procura inferir a determinação de fins a partir da determinação de máximas, algo impossível de ser levado a cabo, desde que máximas sejam apenas determináveis negativamente em relação a fins, sem que os próprios fins possam ser positivamente explicitados.

À primeira vista, as objeções de Allison mantêm-se circunscritas à breve dedução do princípio supremo da Doutrina da virtude. Na verdade, nesta dedução o crítico toma por "question-begging" a caracterização da razão pura prática como aptidão em geral de pôr-se fins.

Segundo Allison, o argumento de Kant, ao procurar fundamentar o princípio da virtude, consiste em mostrar que uma impugnação da possibilidade de haver fins obrigatórios equivale a contestar que a razão pura prática seja prática, ou seja, a máxima que não toma interesse por aquilo que é fim perante a razão pura prática contradir-se-ia a si própria. Para Allison, tal

\footnotetext{
${ }^{1}$ H.E. ALLISON, Idealism and freedom: Essays on Kant's theoretical and practical philosophy. Cambridge: University Press, 1996, 155-168.

2 I bidem, 158.

${ }^{3}$ I. KANT, Metaphysische Anfangsgründe der Tugendlehre 395. Hrsg. von B. Ludwig. Hamburg: Meiner, 1990, 29. "Handle nach einer Maxime der Zwecke, die zu haben für jedermann ein allgemeines Gesetz sein kann".

${ }^{4}$ H.E. ALLISON, op. cit., 158.
} 
resultado não flui, porém, da premissa de que cada máxima contém um fim. De acordo com o crítico, Kant mostra apenas que máximas podem conter fins no sentido de serem "policies for attaining freely chosen ends" 5 . A objeção de Allison retroage sobre o imperativo categórico no sentido de limitá-lo à possibilidade de prescrever condições negativas para a escolha de nossos fins, incapaz que é de indicar positivamente qualquer fim ao qual estejamos imperativamente vinculados. Em suma, Allison concede que a razão pura prática pode servir como fonte de regras para máximas de fins, sem ao mesmo tempo fornecer fins positivos, uma vez que os últimos são sempre e tão-só por nós aceitos livremente.

A posição de Allison incide sobre uma contradição, aventada por Kant, segundo a qual a razão prática não poderia determinar máximas para ações e, em conseqüência, não seria prática como faculdade de fins em geral, se permanecesse indiferente em relação a fins que o são perante ela mesma, não mostrando por eles nenhum interesse. Examinada de perto, essa suposição é considerada por Kant tão-somente contraditória sob 0 aspecto de que seria impossível à razão manter-se indiferente à acolhida ou não de fins próprios a ela e pudesse, além disso, dar-se máximas sem concomitantemente determinar os fins contidos nessas máximas. Determinar um fim a priori equivale a ordenar um fim da razão pura prática. Ao fazê-lo, a razão que prescreve fins determina ao mesmo tempo as máximas, quer dizer, faz desses fins um dever, seja do homem em relação a si mesmo, seja em relação a seus semelhantes.

Com vistas à amplitude das objeções de Allison no âmbito da dedução do princípio supremo da Doutrina da virtude, o presente trabalho propõe-se mostrar que Kant sustenta a ordenação de fins como deveres apenas com o interesse da razão no fato de ela mesma conter fins, ou com o intuito exclusivo de sustentar 0 fato de que os fins propostos pela razão pura prática coincidem com a aptidão geral da razão de fornecer fins, tornando o homem merecedor da vida que acolhe a seu bel-prazer.

\section{O desafio do voluntarismo jusnaturalista}

No prefácio aos Princípios metafísicos da doutrina da virtude, Kant observa que a morte serena (eutanasia) de toda moral segue-se à substituição do princípio da liberdade da legislação interna (eleuteronomia) pelo princípio da felicidade (eudamonia); e acrescenta: "A causa desses equívocos não é outra senão a seguinte: 0 imperativo categórico, do qual procedem ditatori-

5 I bidem. 
almente essas leis, não quer entrar na cabeça daqueles apenas acostumados a explicações fisiológicas" ${ }^{\prime}$.

Por mais incisiva e inambígua que à primeira vista pareça ser, a afirmação enseja equívocos, a menos que esteja devidamente situada. A expressão "explicações fisiológicas" encontra um paralelo no prefácio da Antropologia em perspectiva pragmática, onde se lê que "o conhecimento fisiológico do homem refere-se à investigação daquilo que a natureza faz do homem"7. Ao descartar peremptoriamente, na abertura da Doutrina da virtude, tal conhecimento explicativo como adequado para uma doutrina metafísica dos costumes, Kant ratifica a incompatibilidade entre moral pura e antropologia empírica, postulada na primeira Crítica, onde lemos: "Por isso, a metafísica dos costumes é, propriamente, a moral pura, onde não se toma por fundamento nenhuma antropologia (nenhuma condição empírica)" Apressado seria, porém, satisfazer-se com uma posição excludente entre metafísica dos costumes e antropologia. Depois de haver ratificado mais uma vez a pureza indelével dos princípios morais e sua proveniência a priori, Kant escreve na introdução à M etafísica dos costumes: "Uma metafísica dos costumes não pode ser fundamentada na antropologia, mas

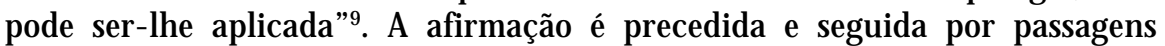
cujo teor explicita um contexto argumentativo distinto da primeira Crítica, chamado por Kant de filosofia prática e cujas partes são a metafísica dos costumes e a antropologia moral. Esse novum programático implica uma alteração sistêmica no que tange à concepção kantiana da pureza filosófica. Enquanto na Crítica da razão pura "a moralidade é a única conformidade das ações à lei que pode ser deduzida inteiramente a priori de princípi$0 \mathrm{OS}^{\prime 10}$, o Kant tardio assegura que "apenas 0 prático segundo leis da liberdade pode ter princípios, que independem de toda teoria; pois, acima das determinações da natureza não há teoria"11.

\footnotetext{
${ }^{6}$ I. KANT, op. cit., 9. "Die Ursache dieser Irrungen ist keine andere als folgende. Der kategorische Imperativ, aus dem diese Gesetze diktatorisch hervorgehen, will denen, die bloss an physiologische Erklärungen gewöhnt sind, nicht in den Kopf".

7 Idem, Anthropologie in pragmatischer Hinsicht. Hrsg von K. Vorländer. 7. Aufl. Hamburg: Felix Meiner, 1980, 3. "Die physiologische Menschenkenntnis geht auf die Erforschung dessen, was die Natur aus dem Menschen macht".

${ }^{8}$ I dem, Kritik der reinen Vernunft B 869. Hrsg. von Raymund Schmidt. 8. Aufl. Hamburg, Meiner, 1956, 755-56. "Daher ist die Metaphysik der Sitten eigentlich die reine Moral, in welcher keine Anthropologie (keine empirische Bedingung) zum Grunde gelegt wird". ${ }^{9}$ I dem, Metaphysische Anfangsgründe der Rechtslehre217. Hrsg. von B. Ludwig. Hamburg: Meiner, 1986, 13. "Das will soviel sagen, als: eine Metaphysik der Sitten kann nicht auf Anthropologie gegründet, aber doch auf sie angewandt werden".

${ }_{10}$ Idem, Kritik der reinen Vernunft B 869, 755. "Nun ist die Moralität die einzige Gesetzmäzigkeit der Handlungen, die völlig a priori aus Prinzipien abgeleitet werden kann".

${ }^{11}$ I. KANT, Metaphysische Anfangsgründe der Rechtslehre 217. Hrsg. von B. Ludwig. Hamburg: Meiner, 1986, 14. “(N)ur das Praktische nach Freiheitsgesetzen kann Prinzipien haben, die von keiner Theorie abhängig sind: denn über die Naturbestimmungen hinaus gibt es keine Theorie".
} 
Supérfluo é assinalar que uma filosofia moral e uma doutrina ética, ancoradas totalmente sobre 0 conceito de liberdade e cujas leis práticas prescrevem ações internas e externas como deveres, imunes a qualquer escala de valores e ordem hierárquica de bens, são, como foram no passado, um atrevimento.

0 atrevimento kantiano consiste em inverter o ônus da prova para quem pretende saber como a razão teórica pode, ela mesma, tornar-se prática. A primeira Crítica limita-se a assegurar que nenhum progresso no âmbito do conhecimento da natureza poderá excluir que estamos certos ao supor um reino da liberdade. Na Fundamentação, a asserção de que a vontade não é outra coisa senão razão prática constitui a marca de seres cuja conduta está em conformidade com as regras da razão que determinam naturalmente 0 que é bom. Como a vontade dos humanos é racionalmente apenas determinável - não sendo jamais espontânea e racionalmente determinada como nos entes santos - o ônus da prova da liberdade cabe a quem quer saber como a razão passa a ser prática, ou, como ela determina a nossa vontade. $\mathrm{Na}$ introdução da segunda Crítica, Kant já abandona tais perguntas e satisfaz-se em expor que a razão pura pode ser prática. A famosa passagem do fato da razão é, a rigor, um feito da razão ${ }^{12}$, e não algo com o qual o agente moral fortuita ou necessariamente se depara mais cedo ou mais tarde. Não se trata, na verdade, de um fato da razão, porquanto essa é prática, mas constitui, sim, um fato para quem deixa que sua razão se torne prática enquanto dá a si mesmo a lei pela qual reflete sua conduta, ao conceber-se como um ser livre, concedendo desse modo realidade objetiva ao conceito da liberdade em sua pessoa. A doutrina do Faktum inverte, no mais tardar, a prova da pergunta acerca da maneira como a razão teórica chega a ser prática ${ }^{13}$.

Para Kant, julgamos nosso comportamento sempre já à luz de critérios morais sem sabermos que somos livres, pois apenas ajuizamos que 0 somos. 0 fato de nos ser dado dessa forma a possibilidade de interpretar e apreciar nosso agir, de maneira continuada e coerente, indica que podemos supor a liberdade. Nós produzimos o reino da liberdade pela ação, e na raiz dessa ação nossos juízos práticos pressupõem a vontade de compreender nosso agir enquanto seres autônomos, vale dizer, como entes determinados não apenas pelas leis conhecidas e desconhecidas da natureza.

A vontade humana que, em primeira mão, assume a razão prática não é um gesto do homo phaenomenon. A cadeia de ações desse homem é incapaz de remeter a um ato empírico anterior à primeira decisão fatual. $\mathrm{Na}$

12 Z. LOPARIC, O fato da razão. Uma interpretação semântica. Analytica. Rio de J aneiro, v. 4, n. 1, 1999, 36.

13 I bidem, 35. "A demonstração da efetividade da lei moral necessariamente precede a demonstração da sua possibilidade, que é feita pela simples análise conceitual, de acordo com o princípio: tudo que é efetivo é possível". 
medida em que a vontade é concebida como ato primevo do animal racional homem, o princípio constitutivo dessa vontade não vincula o seu autor, pois quem pode obrigar pode também desobrigar. Concebida em contrapartida como incondicional numênico, enquanto ser munido de liberdade interior, isto é, com livre-arbítrio, a vontade legisladora antecede o agir humano como a autocompreensão - que os humanos têm deles mesmos - antecipa as descrições que os indivíduos fazem de seus atos, de sua conduta e dos seus modos de ser. Enquanto expressão de vontade, a compreensão incondicionada da razão prática não encontra fundamento último. Segundo Kant, a procura de tal amparo fundacional, que valesse a pena ser conhecido, não somente está condenada ao fracasso, mas também carece de um objeto a ser investigado. Não nos entendemos como seres racionais práticos e tampouco reconhecemos a nossa razão como prática na contemplação, mas a queremos sempre já como prática quando refletimos sobre nosso comportamento, falamos de nossas ações e tomamos posição perante nosso querer. A razão prática é a razão de um ser que se autoentende como agente "porque a razão age em nós"14 e, por extensão, como razão de seres que buscam entender-se com o semelhante sobre o justo e o injusto. Entre todas as querelas, aponta Kant, "nenhuma há que mais suscite a acolhida das pessoas (...), e traga certa animação nas rodas de conversa, do que a discussão sobre o valor moral desta ou daquela ação, pelo qual se deve definir o caráter de uma pessoa qualquer" ${ }^{15}$.

A introdução à Metafísica dos costumes traz tardiamente, pela primeira e única vez, uma distinção terminológica aprimorada para atos do livrearbítrio em relação a uma vontade enquanto razão prática. Kant escreve:

A vontade é, portanto, a faculdade apetitiva não considerada em especial (como 0 arbítrio) em relação à ação, mas muito mais em relação ao fundamento de determinação do arbítrio para a ação, e não tem antes dele mesmo propriamente nenhum fundamento de determinação, mas é, porquanto pode determinar 0 arbítrio, ele próprio a razão prática. Sob a vontade pode estar contido 0 arbítrio, mas também o mero desejo, na medida em que a razão pode determinar em geral a aptidão do desejo $0^{16}$.

\footnotetext{
14 I bidem, 36.

${ }^{15}$ I. KANT, Kritik der praktischen Vernunft 273. Hrsg. von K. Vorländer. 9. Aufl. Hamburg: Meiner, 1967, 175. "Unter allem Räsonieren ist aber keines, was mehr den Beitritt der Personen (...) erregt und eine gewisse Lebhaftigkeit in die Gesellschaft bringt, als das über den sittlichen Wert dieser oder jener Handlung, dadurch der Charakter irgend einer Person ausgemacht werden soll".

16 Idem, Metaphysische Anfangsgründe der Rechtslehre 213. Hrsg. von B. Ludwig. Hamburg: Meiner, 1986, 17. "Der Wille ist also das Begehrungsvermögen, nicht sowohl (wie die Willkür) in Beziehung auf die Handlung, als viel mehr auf den Bestimmungsgrund der Willkür zur Handlung betrachtet, und hat selber vor sich eigentlich keinen Bestimmungsgrund, sondern ist, sofern sie die Willkür bestimmen kann, die praktische Vernunft selbst. Unter dem Willen kann die Willkür, aber auch der blosse Wunsch enthalten sein, sofern die Vernunft das Begehrungsvermögen überhaupt bestimmen kann".
} 
A identificação de vontade e razão prática expressa a incondicionada autodeterminação humana. "Da vontade", assevera Kant, "derivam as leis, do livre-arbítrio as máximas (...). A vontade (...) não pode ser chamada nem de livre nem de não-livre (...). Portanto, só o arbítrio pode ser denominado livre" ${ }^{17}$. Segundo esta versão tardia da liberdade, 0 arbítrio do homem é entendido em oposição ao arbítrio animal, "como capacidade subjetiva de deixar-se determinar pela razão" ${ }^{18}$.

Por um lado, a noção kantiana de autonomia nada tem a ver com o uso cotidiano do termo e, por outro, não implica liberdade de ação. De acordo com o senso comum, autonomia significa liberdade de agir, ou seja, é autônomo quem não está submetido à vontade de outrem e faz de sua vida o que bem entende. A compreensão corriqueira de autonomia não está interessada em saber se por detrás da conduta desimpedida da liberdade de movimentos há uma vontade livre ou pessoas que atuam condicionadas por múltiplos fatores. Para Kant, a liberdade da vontade não é inerente à liberdade de ação e, inversamente, ter liberdade da vontade não requer 0 usufruto da liberdade de agir. Liberdade de ação existe na ausência de impedimentos externos, possíveis de serem colocados por disposição alheia. A liberdade da vontade postula muito mais ou, como Kant formula, exige uma causalidade prenhe de liberdade, portanto, prevê uma formação nãoheterônoma de voluntariedade, incausada seja por leis inerentes à natureza do homem, seja pela educação ou por qualquer outra determinidade cultural. Ao haver causalidade de liberdade, 0 agente toma distância dos determinismos internos e externos que regem a conduta humana e tornase autor de seus atos. A vontade livre constitui, em Kant, uma causação de liberdade que, diferentemente de todas as demais causas no universo, permanece por sua vez incausada. A autonomia kantiana da vontade não conhece antecedentes causais senão condições racionais. A vontade é livre sem delongas e pressupostos - desde que queira - razão por que Kant diz que não pode ser chamada de livre e tampouco de não-livre. Sua eficácia como ratio essendi é imediata, o que explica porque da liberdade apenas temos consciência pela lei moral, na condição de ratio cognoscendi da mesma.

O lugar destinado por Kant ao legislador humano é ocupado por Deus na moderna tradição do direito natural. De acordo com Grotius, uma lei da natureza perfaz uma exigência da razão, feita vinculante pela vontade expressa de Deus. 0 direito natural constitui, para o jusnaturalista holandês, um mandamento da razão, "que indica que é inerente a uma ação

17 I bidem 226, 23. "Von dem Willen gehen die Gesetze aus; von der Willkür die Maximen (...). (D)er Wille (...) kann weder frei noch unfrei genannt werden (...). Nur die Willkür also kann frei genannt werden".

${ }^{18} \mathrm{~V}$. ROHDEN, O humano e racional na ética. Studia kantiana. Rio de J aneiro, v. 1, n. $1,1998,317$. 
uma ignomínia ou uma necessidade moral, com vistas à sua concordância ou não com a natureza racional, e, além disso, indica por que Deus, como o criador da natureza, prescreveu ou proibiu tal ação"19. Segundo Grotius, tais ações são necessariamente prescritas ou proibidas por Deus, ou seja, assim como Deus é incapaz de alterar a aritmética, Ele não tem condições de mudar a ordem moral, estatuindo que não seja mau o que por razão intrínseca é mau ${ }^{20}$. Grotius distingue claramente entre a qualidade moral da ação - oriunda da natureza das coisas e conhecida pela razão - e 0 ordenamento divino que prescreve ou proíbe. A obrigatoriedade de uma lei não decorre diretamente da racionalidade dessa lei, mas advém a ela por um complemento volitivo, expresso no ato pelo qual uma instância autorizada manda fazer ou manda sustar. De acordo com a fórmula grotiana, a lei natural é um mandamento que indica sua concordância com a natureza racional e, com base num ato da vontade divina, prescreve uma conduta em conformidade com a concordância referida pela lei. Em suma, a lei natural contém uma lei que indica e uma lei que prescreve; a primeira identifica uma ação como boa, a segunda faz dela uma obrigação.

A remissão grotiana à vontade de Deus está inserida numa argumentação que não permite considerar a fonte divina do direito natural como supérflua ou complementar. Mas ela já é secundária no sentido de que Deus, dada a racionalidade da ordem natural, faz o que não pode deixar de fazer, isto é, prescreve as ações moralmente devidas e veta o agir moralmente nocivo.

Em F. Suárez encontra-se a constelação matricial do direito natural cristão moderno, a saber: na medida em que Deus não deixa de ordenar o que é intrinsecamente bom, a voluntas do Todo-Poderoso segue ao intellectus da divindade. 0 moralista evita as alternativas, de acordo com as quais a lei natural ou é "lex indicans", provinda da razão de Deus, ou é "lex praecipiens", devedora à vontade do Senhor. No primeiro caso, as leis naturais não são mandamentos, mas contêm indicações cognitivas sobre 0 respectivo conteúdo da lei; no segundo caso, as leis naturais tendem a ser incognoscíveis, providenciadas que são pela livre e insondável vontade de Deus. Eqüidistante dos extremos, o jesuíta escreve: "Considero que se deva trilhar o caminho do meio e acredito que essa seja também a solução de Santo Tomás e dos teólogos. Digo, portanto, primeiro: a lei natural não apenas indica o que é mau e bom, mas contém também sua própria proibição do mal assim como a prescrição do bem"21. Esta objetivação disjuntiva

\footnotetext{
${ }^{19} \mathrm{H}$. GROTIUS, De J ure Belli ac Pacis I,1,X,1, p. 9. "I us naturale est dictatum rectae rationis, indicans, actui alicui, ex eius convenientia aut disconvenientia cum ipsa natura rationali inesse moralem turpidinem, aut necessitatem moralem, ac consequenter ab auctore Deo naturae talem actum aut vetari aut praecipi".

${ }_{20}$ I bidem. "Est autem jus naturale adeo immutabile, ut ne a Deo quidem mutari queat. (...). Sicut ergo ut bis duo non sint quatuor ne a Deo potest effici, ita ne hoc quidem, ut quod intrinseca ratione malum est, malum non fit".
} 
não é, porém, concebida como mera conseqüência dos mandamentos do alto. Suárez assegura que o comando divino também "não é a única razão para o caráter bom ou mau, inerente à observância ou transgressão da lei natural"22. A via média não responde à pergunta crucial acerca da suposta relação, contida na lei natural, entre a intrínseca qualidade moral dos atos humanos e a imperscrutável liberdade dos comandos divinos. 0 teólogo concebe a vontade de Deus como simplesmente livre em suas manifestações externas (simpliciter libera ad extra) e caracteriza como necessitárias (neccessitari) as cadeias seqüências que seguem tais ações exteriores. Assim, o Todo-Poderoso tem que cumprir as promessas emanadas de Sua vontade e, ao querer revelar algo, o revelado por Ele tem que ser a verdade. Suárez conclui, escrevendo: “ $E$, desse modo, Deus não pode querer (...) não proibir a tais criaturas as ações intrinsecamente más e não lhes prescrever as ações necessariamente boas" ${ }^{23}$.

Segundo o teólogo ibérico, a livre criação divina vincula Deus, quer como criador quer como legislador, aos princípios constitutivos do universo. Pelo conhecimento do universo, os homens podem tomar como válidos os princípios objetivos da criação, aos quais o próprio Deus e todos os seres criados encontram-se submetidos. Para Suárez, enquanto Deus está comprometido com sua obra graças à racionalidade interna do primeiro ato da vontade criadora, os homens ficam vinculados aos mesmos princípios devido a comandos externados necessariamente por Deus e necessitariamente obrigatórios para os homens, seus destinatários. Também no prefácio ao De lure Belli ac Pacis, o famoso aforismo "etiamsi daremus non esse Deum"24 ("caso fôssemos supor que não haveria Deus") reporta-se exclusivamente à cognoscibilidade da intrínseca excelência de ações particulares; para Grotius, mesmo se nada soubéssemos de Deus e ignorássemos a fortiori seus mandamentos, ainda assim estaríamos em condições de distinguir o bem do mal.

Kant não revitaliza Deus como artífice moral. Nem a natureza externa nem a natureza do homem adquire qualquer relevância na fundamentação

\footnotetext{
${ }^{21}$ F. SUÁREZ, De Iustitia ac Deo Legislatore II, vi, 5, p. 19. "Mediam viam tenendam censeo, quam existimo esse sententiam divi Thomae et communem theologorum. Dico ergo primo: Lex naturalis non tantum est indicativa mali et boni, sed etiam continet propriam prohibitionem mali et praeceptionem boni".

22 Ibidem II, vi, 11, p. 31. "Dei voluntas, prohibitio aut praeceptio non est tota ratio bonitatis et malitiae quae est in observatione vel transgressione legis naturalis".

${ }^{23}$ I bidem II, vi, 23, p. 40. "I deoque supposita voluntate creandi naturam rationalem cum sufficienti cognitione ad operandum bonum et malum et cum sufficienti concursu ex parte Dei ad utrumque, non potuisse Deum non velle prohibere tali creaturae actus intrinsece malos vel nolle praecipere honestos necessarios".

${ }^{24} \mathrm{H}$. GROTIUS, op. cit. (Praefatio), 3. "Et haec quidem quae jam diximus, locum aliquem haberent etiamsi daremus, quod sine summo scelere dari nequit, non esse Deum, aut non curari ab eo negotia humana: cujus contrarium cum nobis partim ratio, partim traditio perpetua, inseverint (...)".
} 
kantiana da obrigatoriedade moral. "A moralidade consiste, pois", afiança Kant, "na relação de toda a ação com a legislação, através da qual somente se torna possível um reino de fins. Mas, essa legislação tem que encontrarse em cada ser racional mesmo e poder brotar da sua vontade (...)"25. Quem se entende como membro de tal reino da liberdade, se auto-entende ao mesmo tempo como um ser que origina esse reino. "A vontade", escreve Kant, "não está pois simplesmente submetida à lei, mas submetida de tal maneira que tem que ser reputada também como legisladora ela mesma e, exatamente por isso e só então, está submetida à lei (de que ela própria se pode considerar como autora)" 26 .

\section{A resposta ao racionalismo naturalista}

A designação "razão prática" constitui à época de Kant uma novidade no vocabulário moral. 0 nous pratikós aristotélico não é prático em sentido kantiano senão que visa ao meio-termo. 0 novum terminológico só pôde aparecer depois que o cristianismo descobrira a importância da vontade para a moral e, segundo B. Ludwig, "só teve que ser inventado quando, frente aos novos critérios do conhecimento, o saber humano acerca da vontade divina tornara-se problemático e com isso, pelo menos sob visor filosófico, acabou insignificante" ${ }^{27}$. Enquanto a substituição do Criador pela criação de um reino de obrigatoriedades com caráter de coerção e necessitação é considerada bem-sucedida, a novidade ética em relação a Aristóteles não recebe a devida atenção. Por conceber a doutrina ética ancorada sobre regras e não sobre virtudes, a tardia obrigação kantiana como matéria da obrigatoriedade moral, tende a ser preterida em favor de uma concepção ética antropologicamente difusa. M. Gregor admoesta que "uma objeção conhecida faz tempo à ética de Kant - reavivada agora no âmbito da ética da virtude - seria de qualquer maneira fulminante: não

\footnotetext{
${ }^{25}$ I. KANT, Grundlegung zur Metaphysik der Sitten 434. Hrsg. von K. Vorländer. 3. Aufl. Hamburg: Meiner, 1965, 57. "Moralität besteht also in der Beziehung aller Handlung auf die Gesetzgebung, dadurch allein ein Reich der Zwecke möglich ist. Diese Gesetzgebung muss aber in jedem vernünftigen Wesen selbst angetroffen werden und aus seinem Willen entspringen können (...)".

26 I bidem 431, 54. "Der Wille wird also nicht lediglich dem Gesetze unterworfen, sondern so unterworfen, dass er auch als selbstgesetzgebend und eben um deswillen allererst dem Gesetze (davon er selbst sich als Urheber betrachten kann) unterworfen angesehen werden muss".

${ }^{27}$ B. LUDWIG, Die "praktische Vernunft" - ein hölzernes Eisen? Zum Verhältnis von Voluntarismus und Rationalismus. J ahrbuch für Recht und Ethik. Berlin, Bd. 5, 1997, 25. “Und er [der Terminus 'praktische Vernunft'] musste erst erfunden werden, als angesichts neuer Erkenntniskriterien ein menschliches Wissen über den göttlichen Willen fragwürdig und damit zumindest philosophisch endgültig bedeutungslos geworden war".
} 
pode a ética dispensar de todo imperativos categóricos, e com isso prescindir dos conceitos kantianos da obrigação e liberdade?". A tradutora americana é taxativa: "Uma tal crítica mira o coração da filosofia moral de Kant"28.

A razão prática é o coração da doutrina moral de Kant.

Razão prática é vontade, e somente seres racionais têm vontade. "Tudo na natureza", escreve Kant, "age segundo leis. Só um ser racional tem a capacidade de agir segundo a representação das leis, isto é, segundo princípios, ou, só ele tem uma vontade. Como para derivar as ações das leis é necessária a razão, a vontade não é outra coisa senão razão prática" ${ }^{29}$.

O sono profundo, que acomete a quem foi receitado um sonífero, é a conseqüência natural da lei que determina os processos farmacológicos no interior do organismo. Quando ingerimos um medicamento para dormir profundamente, fazemo-lo de acordo com a representação da lei, tendo em vista os efeitos benéficos da substância. Caso se trate de um ente racional destituído de sensibilidade, suficientes são a representação da lei, aliada à intenção de acordar bem-dormido, e o conhecimento do efeito da droga para movê-lo a tomar o sonífero, assim como esse, uma vez ingerido, naturalmente provoca no dormente um sono reparador. Para seres dessa espécie, chamados de santos ou divinos, a ação é subjetivamente imperiosa tão logo a necessidade objetiva esteja configurada pelo fim previamente fixado, exatamente como ocorrem, dadas as causas, as conseqüências inerentes a todos os fenômenos regidos por leis naturais. Para seres não santos, as ações objetivamente necessárias são casuais porque, em tais criaturas, inclinações afetam também o querer, isto é, o agir objetivamente conseqüente segue-se ao vínculo do imperativo. Enquanto nos seres divinos a vontade constitui a aptidão de escolher o que é praticamente bom, a vontade do indivíduo não funciona como mera faculdade de seguir regras, uma vez que é normal que haja tendências que resistam ao uso do sonífero, de modo que preciso vencer-me a mim mesmo, passando por cima da inclinação de ficar inativo e não querer fazer nada, muito embora saiba que o sonífero me fará bem e que é de todo racional providenciar que provo-

${ }_{28}$ M. GREGOR, Kants System der Pflichten in der Metaphysik der Sitten. Ensaio introdutório a Kant. I. Metaphysische Anfangsgründe der Tugendlehre. Hrsg. von B. Ludwig. Hamburg: Meiner, 1990, p. LXV. "Ein schon lange bekannter Einwand gegen die Ethik Kants - der nun im Rahmen der Tugendethik wiederbelebt wird - wäre allerdings vernichtend: kann die Ethik nicht ganz auf kategorische Imperative - und damit auf die Kantischen Begriffe von Verpflichtung und Freiheit - verzichten? Eine solche Kritik zielt auf das Herz der Kantischen Moralphilosophie".

${ }^{29}$ I. KANT, Grundlegung zur Metaphysik der Sitten 412. Hrsg. von K. Vorländer. 3. Aufl. Hamburg: Meiner, 1965, 32. "Ein jedes Ding der Natur wirkt nach Gesetzen. Nur ein vernünftiges Wesen hat das Vermögen, nach der Vorstellung der Gesetze, d.i. nach Prinzipien zu handeln, oder einen Willen. Da zur Ableitung der Handlungen von Gesetzen Vernunft erfordert wird, so ist der Wille nichts anderes als praktische Vernunft". 
que os efeitos benéficos que necessariamente produz no organismo de quem, como eu, preciso de um sono profundo e reparador.

À luz das definições kantianas tardias de vontade e arbítrio, somente seres que agem por imperativo fazem escolhas, ao passo que necessidades divinas não podem, enquanto vontade, serem chamadas nem de livres nem de não livres, uma vez que na vontade pode estar contido não só o arbítrio, mas também o mero desejo. Vontades divinas atuam racionalmente por agirem segundo juízos hipotéticos; assim, por exemplo, seres santos iriam ater-se necessariamente aos princípios da farmacologia, quando em vez de continuar a jogar baralho têm em mente dormir profundamente. Na passagem onde trata dos imperativos de destreza (Geschicklichkeit), Kant diz que, quanto ao querer, é analítica a proposição segundo a qual quem quiser o fim, irá querer também o meio indispensavelmente necessário para alcançá-lo, "pois (...) o imperativo extrai o conceito das ações necessárias para este fim do conceito do querer deste fim (... $)^{\prime 30}$. 0 termo "dever" não é empregado ao longo de todo 0 argumento, porque parece claro o suficiente que algo racionalmente bem-querido é necessariamente algo racionalmente devido. Somente ao final da Fundamentação Kant formula a conexão entre 0 benquisto racional e 0 bem-feito racional, ao apostrofar: "O dever moral é, pois, um querer necessário próprio ao ser humano como membro de um mundo inteligível, e só é pensado por ele como dever na medida em que se considera ao mesmo tempo como membro do mundo sensível" ${ }^{31}$. Em contrapartida, a insistência de que Kant parte 0 homem artificialmente em ser-de-razão e ser-de-sensibilidade subestima a alternativa segundo a qual é possível, por capricho, querer que seres humanos sejam tão-somente racionais ${ }^{32}$.

Um princípio categórico apresenta uma ação objetivamente necessária à revelia de qualquer fim determinado possível. De acordo com o parágrafo $7^{\circ}$ da segunda Crítica, o princípio categórico perfaz a lei fundamental da razão pura prática: "Age de tal modo que a máxima da tua vontade possa valer sempre ao mesmo tempo como princípio de uma legislação universal"33. Tal lei fundamental não é essencialmente prescritiva, mas é apresentada por Kant como sentença descritiva, quando escreve na introdução à Metafísica dos Costumes: "pela primeira [a lei], a ação é concebida como dever, a qual [a lei] é um simples conhecimento teórico da possível de-

\footnotetext{
30 I bidem 417, 38. “(...) und der Imperativ zieht den Begriff notwendiger Handlungen zu diesem Zwecke schon aus dem Begriff eines Wollens dieses Zwecks heraus (...)".

31 I bidem 455, 81. "Das moralische Sollen ist also eigenes notwendiges Wollen als Gliedes einer intelligibelen Welt und wird nur sofern von ihm als Sollen gedacht, als er sich zugleich wie ein Glied der Sinneswelt betrachtet".

32 E. TUGENDHAT, Vorlesungen über Ethik. 3. Aufl. Frankfurt a/Main: Suhrkamp, 1995, 160. "Der Mensch fällt jetzt in zwei Teile, Vernunft- und Sinnenwesen, auseinander". ${ }^{33}$ I. KANT, Kritik der praktischen Vernunft 54. Hrsg. von K. Vorländer. 9. Aufl. Hamburg: Meiner, 1967, 36. "Handle so, dass die Maxime deines Willens jederzeit zugleich als Prinzip einer allgemeinen Gesetzgebung gelten könne".
} 
terminação do arbítrio, isto é, de regras práticas" ${ }^{34}$. Somente no agir dos humanos, porquanto suas ações são determináveis pela razão, a lei fundamental da razão prática adquire forma prescritiva. Destinada a seres divinos ou humanos, a proposição é simultaneamente valorativa, ou seja, ela indica uma vontade que se qualifica à autonomia e nomeia assim o distintivo da 'boa vontade'. "Uma vontade", escreve Kant, "cuja máxima é sempre conforme a esta lei é boa absolutamente, em toda a intenção, e é a condição suprema de todo o bem" ${ }^{35}$.

Kant insiste sobre a importância de seu método crítico de definir o moralmente bom como não condicionado pelo predicado não-moral bom, ao observar que o paradoxo do método "explica de uma só vez a causa motivadora de todos os erros dos filósofos quanto ao princípio supremo da moral" ${ }^{36}$. Explicado o paradoxo do método numa crítica da razão prática, a determinação do bom pela fórmula do dever é distendida intuitivamente aos imperativos hipotéticos, quando chamamos de bom um recurso que se presta excepcionalmente bem para alcançar um fim condicionado às propriedades desse recurso como meio. 0 caráter imperativo desse meio, como recurso verdadeiramente bom, cessa tão logo o agente se desfaz do objetivo proposto. Quem não ingere um sonífero de boa qualidade, não obstante pretenda dormir e saiba que sem tal recurso não terá sono, é inconseqüente enquanto não abandona o objetivo de ferrar no sono. Tal inconseqüência condicional valeria também para juízos com antecedente moralmente nãoindiferente, caso não houvesse uma coação específica que decretasse a necessidade objetiva das leis da razão e fizesse do princípio valorativo da boa vontade, como condição suprema de todo bem, um imperativo categórico.

\section{A aparente antinomia da coação ativa $e$ passiva}

A introdução à Doutrina da virtude divide os deveres em deveres de direito e de virtude. "A doutrina do direito", escreve Kant, "só tinha a ver com a condição formal da liberdade exterior (...), isto é, com o direito. A ética, pelo contrário, oferece ainda a matéria (um objeto do livre-arbítrio),

\footnotetext{
34 Idem, Einleitung in die Metaphysik der Sitten. Metaphysische Anfangsgründe der Rechtslehre 218. Hrsg. von B. Ludwig. Hamburg: Meiner, 1986, 28. “Durch das erstere [das Gesetz] wird die Handlung als Pflicht vorgestellt, welches ein blosses theoretisches Erkenntnis der möglichen Bestimmung der Willkür, d.i. praktischer Regeln ist".

${ }^{35}$ Idem, Kritik der praktischen Vernunft 109. Hrsg. von K. Vorländer. 9. Aufl. Hamburg: Meiner, 1967, 73. "(E)in Wille, dessen Maxime jederzeit diesem Gesetze gemäss ist, ist schlechterdings, in aller Absicht gut und die oberste Bedingung alles Gute".

36 I bidem 112, 75. "Diese Anmerkung, welche bloss die Methode der obersten moralischen Untersuchungen betrifft, ist von Wichtigkeit. Sie erklärt auf einmal den veranlassenden Grund aller Verirrungen der Philosophen in Ansehung des obersten Prinzips der Moral".
} 
um fim da razão prática, que ao mesmo tempo é apresentado como fim objetivamente necessário, quer dizer, como fim para o homem" ${ }^{37}$.

A lei do direito é, igual ao imperativo categórico, um princípio formal e negativo ${ }^{38}$. Trata-se de um princípio de universalização que exclui a adoção de condutas cujo parâmetro não seja universalizável. A conclusão da necessidade moral de omitir-se, adquirida da impossibilidade moral de uma ação, é racionalmente inevitável, contrariamente à necessidade moral de agir, tomando-se por base a mera eventualidade moral de uma ação. 0 objeto do dever de direito é uma ação a cuja execução um outro me pode obrigar, valendo-se da lei do direito que o habilita à coerção externa segundo a lei da não-contradição. De resto, cada um pode perseguir na coexistência jurídica com os demais os fins que preza a bel-prazer. "Portanto", conclui Kant, "o princípio supremo do direito é uma proposição analítica"39.

Ao abstrair dos fins ocasionais do livre-arbítrio, a fórmula categórica do dever moral parece inadequada para estabelecer fins objetivos. 0 que faz falta é a prova de que na ética é possível fundamentar máximas de fins segundo princípios morais, de modo que seja possível indicar os objetivos que nos temos de fixar e que devemos perseguir. 0 problema da derivação dos deveres de virtude consiste em saber como o imperativo "tu deves fazer disso ou daquilo um fim para ti mesmo" pode provir do princípio formal de toda a obrigação, a saber: "Age de tal modo que a máxima de tua ação possa tornar-se uma lei universal". Enquanto a última proposição se satisfaz em não ser transgredida, a primeira é a lei dos fins que se deve ter e perseguir, mas cuja efetivação depende de conhecimentos especiais, da aptidão individual e do senso de oportunidade. A impossibilidade de determinar a priori os melhores meios para alcançar o fim proposto faz com que o princípio ético de ter fins limite-se a ser lei formadora de máximas $^{40}$, ou seja, os deveres de virtude abarcam um raio mais amplo do que o vínculo das obrigações jurídicas. "Pois", escreve Kant, "se a lei somente pode ordenar a máxima das ações, não as próprias ações, isto é um sinal de que concede à observância um espaço de ação para uso do livre-arbí-

\footnotetext{
${ }^{37}$ I. KANT, Metaphysische Anfangsgründe der Tugendlehre 380. Hrsg. von B. Ludwig. Hamburg: Meiner, 1990, 12-13. "Die Rechtslehre hatte es bloss mit der formalen Bedingung der äusseren Freiheit (...), d.i. mit dem Recht zu tun. Die Ethik dagegen gibt noch die Materie (einen Gegenstand der freien Willkür), einen Zweck der reinen Vernunft, der zugleich als objektiv-notwendiger Zweck, d.i. für den Menschen als Pflicht vorgestellt wird, an die Hand".

${ }^{38}$ W. KERSTING, Wohlgeordnete Freiheit. I mmanuel Kants Rechts- und Staatsphilosophie. Frankfurt a/Main: Suhrkamp, 1993, 182. "Das Rechtsgesetz ist wie der kategorische I mperativ ein formales und negatives Prinzip".

39 I. KANT, op. cit. 396, 30. "Also ist das oberste Rechtsprinzip ein analytischer Satz". ${ }^{40} \mathrm{M}$. BAUM, Probleme der Begründung Kantischer Tugendpflichten. J ahrbuch für Recht und Ethik. Berlin, Bd. 5, 1997, 43-44.
} 
trio, vale dizer, não pode indicar com exatidão como e quanto, pela ação, deva ser efetuado a favor do fim que ao mesmo tempo é dever"41.

Formulado negativamente, o princípio supremo da virtude consiste na proibição da indiferença de minhas máximas frente a possíveis fins obrigatórios. A impossibilidade moral de tal desinteresse deriva da contradição de conceber uma razão prática que não fosse determinar as máximas para ações que contêm cada vez um fim e, desse modo, não seria razão prática. "Mas, a razão pura não pode", escreve Kant, "decretar fins a priori senão enquanto os anuncia ao mesmo tempo como dever; tal dever denomina-se, então, dever de virtude" ${ }^{42}$. Quem, portanto, não toma por fim para si a razão prática como exímia faculdade dos fins, Ihe é indiferente ou permanece inativo perante ela, renuncia à possibilidade de determinar ele próprio as máximas e os fins que as compõem e não pode, assim, fazer de tal abstinência racional uma não-contradição da razão.

Kant registra expressamente que o princípio da doutrina da virtude, ao ir como imperativo categórico além do conceito da liberdade externa e conectar ainda, segundo leis gerais, o conceito de direito com um fim, não fornece prova alguma, mas permite acertadamente uma dedução originada da razão pura prática ${ }^{43}$. A dedução introduz um princípio de fins que, à luz das leis formais da moral e do direito, constitui um novo princípio material, a saber: "o que na relação dos homens, quer para consigo mesmo quer para com os outros, pode ser fim, isto é fim perante a razão pura prática, pois ela é uma faculdade por excelência dos fins"44. A dedução mostra que somente a auto-obrigação é adequada à legislação ética. Ao promover moralidade, a lei ética exige de mim que eu a faça lei de minha própria vontade, diferentemente do que ocorre com a legislação jurídica, na qual posso ser obrigado por outrem a cumprir heteronomamente minhas obrigações, uma vez que a cada dever jurídico corresponde um direito subjetivo alheio. Ainda que submetido a ambas, a legislação ética exige mais de mim do que a legislação jurídica, ou seja, me impõe a condição de ser 0 sujeito dela. Tal posição, eu a tenho quando tão-só a razão determina minha vontade e faz com que eu tome a lei não apenas como princípio

\footnotetext{
${ }^{41}$ I. KANT, Metaphysische Anfangsgründe der Tugendlehre 390. Hrsg. von B. Ludwig. Hamburg: Meiner, 1990, 23. "Denn wenn das Gesetz nur die Maxime der Handlungen, nicht die Handlungen selbst, gebieten kann, so ist's ein Zeichen, dass es der Befolgung (Observanz) einen Spielraum (latitudo) für die freie Willkür, überlasse, d.h. nicht bestimmt angeben könne, wie und wieviel durch die Handlung zu dem Zweck, der zugleich Pflicht ist, gewirkt werden solle".

42 I bidem 395, 30. "Die reine Vernunft aber kann a priori keine Zwecke gebieten, als nur sofern sie solche als Pflicht ankündigt; welche Pflicht alsdann Tugendpflicht heisst".

43 Ibidem, 29-30. "Dieser Grundsatz der Tugendlehre verstattet, als ein kategorischer Imperativ, keinen Beweis, aber wohl eine Deduktion aus der reinen praktischen Vernunft". ${ }^{44}$ I bidem, 30. "Was im Verhältnis der Menschen, zu sich selbst und anderen, Zweck sein kann, das ist Zweck vor der reinen praktischen Vernunft".
} 
organizacional das ações, mas como motivo exclusivo de meu agir. Sujeito da legislação ética torno-me ao agir moralmente, ao passo que da legislação jurídico-externa sou de qualquer maneira sempre já sujeito.

Ao definir a ética como o sistema dos fins da razão pura prática, Kant concebe a obrigação jurídica como auto-obrigação deslocada para a esfera intersubjetiva, de modo que a coerção externa passa, por assim dizer, a figurar como equivalente mecânico-causal da razão prática motivadora. Enquanto sistema de fins, a ética exclui a possibilidade de que alguém venha a ser forçado fisicamente a assumir fins alheios à sua vontade. $\mathrm{Meu}$ semelhante pode forçar-me a fazer algo que não quero fazer, mas não está em condição de obrigar-me a fazer disso que cumpro sob seu comando 0 meu fim, muito embora eu não possa tomar algo por fim sem que o tenha estabelecido para mim mesmo como fim. Essa referência volitiva do que é fim objetivo para mim contém, segundo Kant, "uma contradição intrínseca: um ato da liberdade que ao mesmo tempo não é livre"45. A contradição desaparece tão logo o fim posto constitui também simultaneamente um dever, já que nesse caso me imponho a mim mesmo uma obrigação, o que por certo coaduna com a liberdade. "Fim é um objeto do livre-arbítrio", expõe Kant, "cuja representação o determina para uma ação (pela qual 0 fim é produzido)" ${ }^{46}$. Como ninguém pode ter um fim sem fazer do objeto do arbítrio o seu próprio fim, o fato de homens terem fins quaisquer para ações constitui um ato da liberdade do sujeito que age, e não resulta de um efeito da natureza. "Dentre esses fins", continua Kant, "deve haver também alguns que são (isto é, de acordo com seu conceito) simultaneamente deveres. Caso deles não houvesse nenhum, e uma vez que nenhuma ação está desprovida de um fim, todos os fins valeriam para a razão prática apenas como meios para outros fins, e um imperativo categórico seria impossível; o que suprime toda doutrina ética" ${ }^{47}$.

A coerção al heia constitui-se em dever quando exercida de acordo com uma lei originada do princípio formal da vontade. Ao cumprir o dever jurídico por respeito à lei, ele é repassado para os domínios da legislação ética, onde perfaz uma obrigatoriedade da virtude, chamada por Kant de obligatio ethica, cuja característica consiste em admitir para as exigências da razão somente o motivo do dever como imperativo de execução. A doutrina da virtude passa assim genericamente a ser doutrina dos deveres

\footnotetext{
45 I bidem 381, 14. "Das letztere ist ein Widerspruch mit sich selbst: ein Akt der Freiheit, der zugleich nicht frei ist".

46 Ibidem 384, 17. "Zweck ist ein Gegenstand der freien Willkür, dessen Vorstellung diese zu einer Handlung bestimmt (wodurch jener hervorgebracht wird).

47 I bidem 385, 18. "Unter diesen Zwecken aber muss es auch einige geben, die zugleich (d. i. ihrem Begriffe nach) Pflichten sind. Denn gäbe es keine dergleichen, so würden, weil doch keine Handlung zwecklos sein kann, alle Zwecke für die praktische Vernunft immer nur als Mittel zu anderen Zwecken gelten, und ein kategorischer Imperativ wäre unmöglich; welches alle Sittenlehre aufhebt".
} 
éticos, por adicionar às obrigações de direito o componente motivacional que identifica deveres cumpridos por respeito à lei, sem que tal cumprimento, só por isso, faça do fim um dever. Afora as obrigações ético-indiretas, a ética tem para Kant ainda deveres próprios, estabelecidos por leis oriundas exclusivamente de minha vontade. Tais deveres tomam por referência objetivos meus e fazem da doutrina da virtude uma doutrina de fins. 0 dever de ter e perseguir tais fins, Kant o chama de officium ethicum sive virtutis. Somente a autocoerção, enraizada no meu arbítrio como liberdade interna, é livre coação e distingue-se formalmente da coerção por meio da qual uma inclinação é sustada por propensão adversa, assim quando ajo legalmente ao cumprir uma obrigação jurídica para não acabar sendo coagido a fazê-lo contra a minha vontade.

À primeira vista, ter um dever para consigo mesmo afigura-se contraditório, pois o autor da obrigação teria a cada momento condições de desobrigar o objeto da obrigação do vínculo auto-imposto pelo eu ativo ao eu passivo da mesma identidade numérica. A resolução da aparente antinomia é providenciada por Kant à luz da bipolaridade antropológica do conceito moral de respeito, próprio ao ser humano enquanto animal racional sensível (homo phaenomenon) e, simultaneamente, enquanto personalidade dotada de livre-arbítrio (homo noumenon), "de modo que", conclui Kant, "o homem (...) pode, sem cair em contradição consigo próprio, (...) reconhecer uma obrigação para consigo mesmo"48.

\section{Bibliografia}

ALLISON, Henry E. Idealism and freedom. Essays on Kant's theoretical and practical philosophy. Cambridge: University Pfress, 1996.

BAUM, Manfred. Probleme der Begründung Kantischer Tugendpflichten. Jahrbuch für Recht und Ethik. Berlin, Bd. 5, 1997.

GREGOR, Mary. Kants System der Pflichten in der Metaphysik der Sitten. Ensaio introdutório a Kant. I. Metaphysische Anfangsgründe der Tugendlehre. Hrsg. von B. Ludwig. Hamburg: Meiner, 1990.

HECK, José N. Autonomia, sentimento de respeito e direito. Veritas. Rio de Janeiro, v. 46, n. 4, 2001.

KANT, Immanuel. Metaphysische Anfangsgründe der Rechtslehre. Hrsg. von B. Ludwig. Hamburg: Meiner, 1986.

\footnotetext{
48 Ibidem 418, 54. "so dass der Mensch (in zweierlei Bedeutung betrachtet), ohne in Widerspruch mit sich zu geraten (weil der Begriff vom Menschen nicht in einem und demsel ben Sinn gedacht wird), eine Pflicht gegen sich selbst anerkennen kann".
} 
, Metaphysische Anfangsgründe der Tugendlehre. Hrsg. von B. Ludwig. Hamburg: Meiner, 1990.

, Kritik der praktischen Vernunft. Hrsg. von K. Vorländer. 9. Aufl. Hamburg: Meiner, 1967.

Anthropologie in pragmatischer Hinsicht. Hrsg von K. Vorländer. 7. Aufl. Hamburg: Felix Meiner, 1980.

KERSTING. Wohlgeordnete Freiheit. Immanuel Kants Rechts- und Staatsphilosophie. Frankfurt a/ Main: Suhrkamp, 1993. , Moderne Freiheit IV: Liberale Eugenik, 2002 (mimeo).

LOPARIC, Zeljko. O fato da razão. Uma interpretação semântica. Analytica. Rio de Janeiro, v. 4, n. 1, 1999.

LUDWIG, Bernd. Kants Rechtslehre. Hamburg: Meiner, 1988 (Kant-Forschungen). ROHDEN, Valério. O humano e racional na ética. Studia kantiana. Rio de Janeiro, v. 1, n. 1 .

TUGENDHAT, Ernst. Vorlesungen über Ethik. 3. Aufl. Frankfurt a/Main: Suhrkamp, 1995.

Endereço do autor:

Av. T-4 C/ T-65 - Setor Bueno

Ed. B. Landeiro, 1077/ A 903

74.230-120 Goiânia GO

e-mail heck@internetional.com.br 